\title{
The Impact of Leaders' Characteristics and their Behavior to the Employee Performance in the Hotel Industry in Sri Lanka
}

\author{
KARUNATHILAKE L P V \\ Osuki Ayurweda Pvt. (Ltd) \\ SRI LANKA \\ karunathilakev@gmail.com
}

\begin{abstract}
:-
This study highlights the importance of leaders' characteristics and behavior as main aspects that could affect the employee performance of Hotel Industry in Sri Lanka. According to the preliminary survey, researcher identified that there are labor turnover and high level of absenteeism due to the employees' dissatisfaction and unsatisfactory working environment effect to decrease the employee performance level. There were three objectives of study, the key objective is “(i) to examine the leaders' characteristics and their behavior which determine the employee performance, and specific objectives are (ii) to identify the extent to which worker participation is obtained for making decisions, (iii) to provide a better set of suggestions to get the leadership styles in this industry smoothen". Construction of conceptual model using major variables such as leaders' characteristics, behavior and employee performance. Particularly, to collect the primary data researcher used personal interviews, and observations with two types of questionnaires. Altogether 105 managers and non-managers working in fourteen star hotels (two managers and four non-managers from each hotel) were selected for the survey. Conclusions were made from the study after carrying out detail scientific analyses of data using correlation and regression statistical tools and software, SPSS 2007 was used to analyze the data. The conclusions are that the leaders' characteristics and behavior are positively correlated with employee performance and implementing participative leadership style for hotels and considering worker participation in taking decisions. Based on the findings of the study number of recommendations were made to the management of hotels to get the performance improved in the hotels in Sri Lanka.
\end{abstract}

Key Words: - Leaders' characteristics, Employees performance, Behavior, Attitudes and Values.

\section{Introduction}

After the introduction of economic liberalization policy in 1977 , the service sector took a larger place all over the economy. As a part of the service sector, hotel industry makes towards the Sri Lankan economic development and increases the national income of the country. Therefore subject to this it is viewed as conducting a study on hotel industry is thoroughly significant. The dynamic nature of today's hotel industry gives both rewards and challenges to managers. As we understood hotel industry is a high labor intensive industry, the most important aspect of industry success is leadership. Hotel industry survives and grows because of the performance of their employees. An effective leader or manager is not only able to influence subordinates, but is also able to ensure that they perform their best. The biggest challenge faced by managers as leaders how to engage the 
hearts and minds of people to increase their performance in order to achieve certain goals and objectives. In all causes hotel managers must exhibit organizational abilities and qualities of leadership to motivate the staff so that their skills are used effectively. Organizations depend on people for effective performance and the people depend on their organizations for resources and co-ordination with other people whose work is important for their success and to the organization as a whole. To improve employees' performance, managers of any organization need to promote the various skills or attributes such as employees' positive attitudes, skills upgrading, team work, training and development etc. positive work related attitudes of employees are likely to contribute to job satisfaction, ensure their involvement in work processes and commitment to the achievement of organizations' objectives. Employees who have job satisfaction, job involvement and organizational commitment that are employees' positive work related attitudes will make them to get closer to their organization and to make useful contribution to enhance efficiency and effectiveness with continuous improvement.

\subsection{Research Problem}

After studying several researches and considering the overall hotel industry, the researcher examined during the past years labor turnover, decreasing labor stability and high level of absenteeism prevailed in the hotel industry. Employed population in the trade and hotels sector declined from 15.3 to 14.9 in2007and from 14.9 to 14.3 in2008 (Central Bank Annual Report 2008). Therefore managers as leaders should take the responsibility to achieve their target. In all cases hotel managers must exhibit organizational abilities and qualities of leadership to motivate the employees, so that their skills are used effectively.

\subsection{Research Questions}

Consistent with the above problem, research questions aroused.

I. Are there any relationship between leaders' characteristics and behavior with employee performance in the hotel industry in Sri Lanka?

II. How far does management get the worker participation for making decisions?

\subsection{Significance}

One of the national income earning sectors, hotel industry plays a major role towards achieving the current fourth foreign exchange earner position to the top spot (Bernard Goonathilake, Sunday Observer, June 7, 2009). According to him the current earnings are around US \$ 450 million and it will pass the US one billion mark when the number of tourist arrivals double. The composition of employed population, hotel and restaurant sector contributes 16.9 in 2007 and 17.7 in 2008 in all service sector employment.

The employees of the hotel industry should keep up and improve their job satisfaction as key partners of this development process. To increase job performance it is essential as prior requirement to attain job satisfaction, low absenteeism and low turnover and so on. In increasing those factors there should be good leadership behavior. 


\subsection{Objectives}

Key objective of the study is to examine the leaders' characteristics and their behavior to determine the employee performance in the hotel industry.

Specific objectives are:

I. To examine the role played by leadership as an intervening factor in respect of employee performance.

II. To provide a better set of suggestions to get the leadership styles in this industry smoothen.

\section{Leaders' Characteristics, Leaders' Behavior and Employee Performance.}

\subsection{Leaders Characteristics}

Leaders are people who do the right things (Warren Bennis, "On becoming a leader", 1982). At the head of the group is the leader, equally as important as its followers, but can make or break the group. The basic role of a leader is to foster mutual respect and build a complementary team where each strength is made productive. Leader establishes direction by developing a vision of the future; then they align people by communicating this vision and inspiring them to overcome hurdles. Management consists of implementing the vision and strategy provided by leaders, coordinating and staffing the organization, and handling day-to-day problems.

Leaders' characteristics define as, a leader has certain inherent qualities and traits which assist him in playing a directing role and wielding commanding influence over others. Some of these traits are(according to Jago, 1982); Energy, Drive, Appearance, Present ability, A sense of cooperativeness, Enthusiasm, Personality, Initiative, Intelligence, Judgment, Self-confidence,
Sociability, Tact and diplomacy, Moral courage and integrity, will power and flexibility, Emotional stability and knowledge of human relations. In order to carry out the study on leaders' attitudes towards employee performance, it is important to develop a solid conceptual background, which provide reference to support the analytical stage of the study. Attitudes are the mental, moral, and ethical dispositions adopted by individuals to other and the situations environment in which they find themselves. Attitudes are evaluative statements either favourable or unfavourable concerning objects, people or events, attitudes represent feelings and beliefs of individuals towards others. An attitude is defined as a persistent tendency to feel and behave in a particular way towards some object (Luthans, 2002).

\subsection{Leader's Behavior}

Research studies conducted by (Katz, Maccoby and Morse, 1957) suggested that leadership behavior can be defined along employee- centered dimensions and production- centered dimension complementing each other so that the employees' performance and productivity are enhanced. Further in-depth investigations into this approach have been conducted at Ohio State University (Stodgill R., and A.E, Coons, 1957) these studies isolate two particular factors affecting the leadership dimension. They are; consideration and initiating structure (Blake and Mouton, 1978) have identified five coordinates that reflect various styles of leader behavior. The managerial grid figure and these styles are shown as; 
Figure 1: Managerial grid diagram

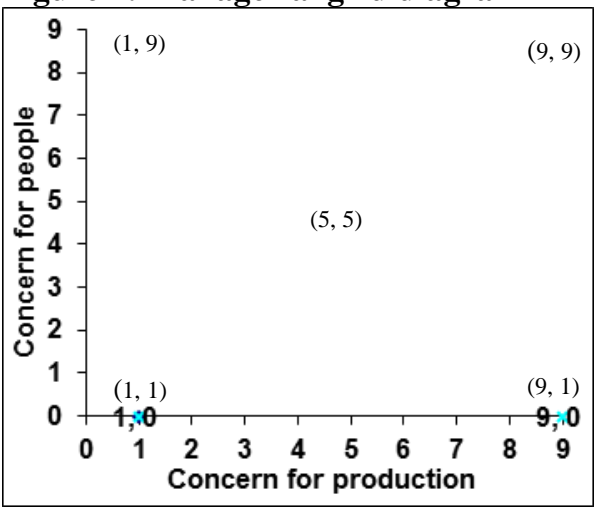

Source: Based upon Robert R. Blake and Jane S.Mouton, "The developing Revolution in management practices". Journal of the American Society Training Directors. Vol.16, No.7 (1962), pp29-52

The managerial grid diagram as shown above can be interpreted as:

- Coordinates (1.1). This represents an impoverished management and the manager makes minimum efforts to get the work done. Minimum standards of performance and minimum worker dedication.

- Coordinates (9.1). Excellent work design. Well established procedures. Minimum workers interference. Orderly performance and efficient operations.

- Coordinates (1.9). Personal and meaningful relationship with people friendly atmosphere and high moral. Loosely structured work design.

- Coordinates (9.9). Ultimate in managerial efficiency. Thoroughly dedicated people.

- Coordinates (5.5). Known as the middle-of-the-road management style, it is concerned with balancing the necessity to get the work done while maintaining worker moral at a satisfactory level. The goal is to achieve adequate organizational performance.
According to Szilagyi and Wallace (1983), there are four contingency variables that influence a leaders' behavior. First, there are the characteristics of the leader himself. These characteristics include the personality of the leader relative to his ability to respond to situational pressures as well as his previous leadership style in similar situations. The second variable relates to the characteristics of the subordinates. The subordinates are important contributors to a given operational situation. The situation will very much depend upon whether the subordinates prefer a participative style of leadership and decision making what are their motivations in this situation. The third factor involves the group characteristics. The fourth situational factor relates to the organizational structure. The organizational structure is the formal system of authority, responsibility and communication within the company.

\subsection{Relationship between Leaders Characteristics and Leaders Behavior}

There are several factors which affect leaders' characteristics in the organization and which can mainly be categorized into three, namely, organizational factors, personal factors and other factors (Breckler, 1984). Organizational factors include reward system, quality of supervision, working conditions, work itself, mission and goals of organization etc. personal factors include personality, involvement with the job, personal carrier goals, expectation, opportunity to use ones knowledge, willingness to adhere with organizational culture and goals, availability of alternate job opportunities, subordinate characteristics etc. other factors include co-workers, environment, legal factors etc. These factors affect once employees' 
job performance through changing leaders' characteristics and leaders' characteristics lead to behavioral changes which ultimately affect performance of the organization. According to the contingencies model leaders characteristics directly affect to the performance through leaders behavior. So far discussions were made on what attitudes perform for people and the relationship of attitudes with employees' behavior and job performance.

\subsection{Employee Performance}

Sometimes, performance is confused with behavior. Performance should be view as the end result and behavior as the means to that end. Behaviors thus the action that can contribute to accomplishments (Kraus, 1995). Performance is a consequence of employees' manifest behavior at work. Performance is defined as the record of outcomes produced on specified job functions or activities during a specified time period. Performance on the job as a whole would be equal to the sum or average of performance on the major job functions or activities. Performance refers to the result or outcomes of work it deals with the outcomes, results, and accomplishments achieved by a person, group or organization (Krause, 1995). The leadership behavior is directly related to individual and group work activity, loyalty of the group, absences, turnovers and employee morale. Many studies have been conducted in order to identify and separate such characteristics and personal traits that are unique to the behavior of successful leaders.

\subsection{Relationship between Leaders' Characteristics, Behavior and Employee Performance.}

A leader has certain inherent qualities and traits which assist him in playing a directing role and wielding commanding influence over others. Some of these traits, according to Jago (Jago, Arthur G., "Leadership perspectives in theory and research". Management science, March 1982) are: Energy, drive, appearance, present ability a sense of Cooperativeness, Enthusiasm, Personality- height and weight Initiative intelligence, Judgment, self- confidence, sociability, tact and diplomacy, moral courage and integrity, emotional stability, knowledge of human relations. The leadership behavior is used in combination with work groups' contingencies to predict performance outcome. According to Szilagyi and Wallace (1983) there are four contingency variables that influence a leaders' behaviour: one of the variables is leaders' characteristics.

Performance should be viewed as the end result and behavior as the means to that end. Performance on the job as a whole would be equal to the sum or average of performance on the major job functions or activities. When effort is meaningfully direct to achieve task goals it becomes performance behavior.

Leadership Styles, One of the main aspects of leaders' behavior is leadership styles. The beginnings of leadership may be defined as the art of influencing and inspiring subordinates to perform their duties willingly, competently and enthusiastically for achievement of group objectives. At the beginning of leadership research during World War 1 which concerned with the identification and measurement of traits that differentiate leaders' followers.

Although such traits were discovered, they proved to be disappointing in that they did not contribute to the selection and placement of persons for positions of leadership. Over the last 80 years, a number of different theories and approaches to studying leadership have 
been developed. Leadership has been defined by different people from several angles and some of them are discussed below.

Leadership is both a process and property. The process of leadership is the use of no coercive influence to direct and coordinate the activities of the members of an organized group towards the accomplishment of group characteristics attributed to those who perceived to successfully employ such influence (Stogdill, 1976).It is important to recognize what this definition includes and what it excludes. Leadership is not only some quality or characteristic that one possesses or is perceived to possess; it can be something that one does. It therefore can describe an act as well as a person. Leadership does not involve the use of force, coercion or domination and is not necessarily implied by the use of such titles as manager, supervisor or superior. In this respect, the definition provides a conceptual distinction between leadership processes and motivational processes. Leadership is therefore distinct from "supervision" or what might be termed "headship" (Jacobs, 1971).

Leadership is an intangible and its effectiveness can best be judged by the behavior and attitudes of followers. Even though, personal backgrounds and personalities differ widely, some of the factors such as, education and socioeconomic status are poor indicators of judgments of successful leaders. However, some behavioral characteristics may be common to most of the successful and effective leaders. According to (Breckler, 1984), mainly three factors affect leaders' characteristics, namely, organizational, personal and other factors. Organizational factors include reward system, quality of supervision, working conditions work itself, mission and goals of organization etc. personal factors include personality, involvement with the job, personal career goals, expectation, opportunity to use ones knowledge, willingness to adhere with organizational culture and goals, availability of alternate job opportunities etc. other factors include co-workers, environment, legal factors etc. these factors affect ones employees' job performance through changing leaders' characteristics and leaders' characteristics lead to behavioral change with ultimately affect performance of the organization.

\section{Conceptual Frame Work}

The literature review provided various theoretical arguments to form the basis of the study. The outcome of the review helped conceptualize the study. The conceptual model was constructed associating the independent variables and dependent variables extracted from the literature review from contingency theories. Having taken the interrelationship between each independent variable with dependent variable into consideration the respective model (figure 2) was designed below.

\section{Figure 2: Conceptual Model}

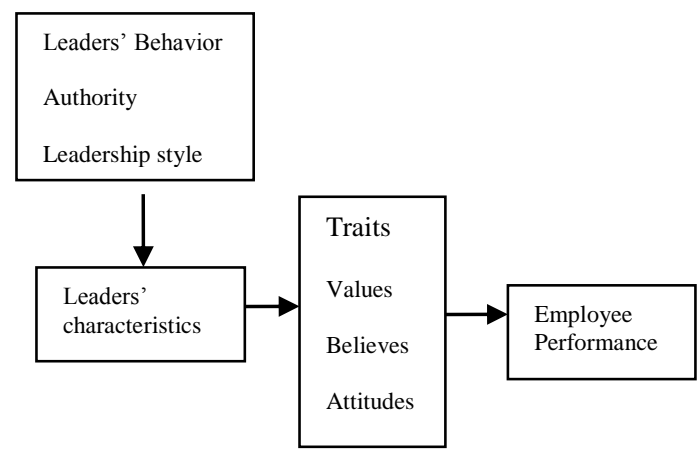

\section{3. (a) Methodology}

Both primary and secondary data were collected for this study. As this study is empirical in nature, as far as possible an attempt was made to collect primary data. Secondary data were collected through 
Text books, journal articles and web sites relevance to the study. Primary data were collected by interviewing respondents and using two types of questionnaires. These questionnaires distributed to the employees (Randomly selected sample), leaders and managers (junior managers and executives) working in fifteen leading star hotels in Sri Lanka.

\subsection{Population and Sampling}

The sample consisted of 15 star graded hotels from all over the country and the respondents selected through their human resource managers. Each of the fifteen hotels in the sample were issued with 30 questionnaires, thus in total $30 \times 7=210$ (there are two kinds of questionnaires, 7 employees and 7 leaders) questionnaires were distributed. In selecting the sample, the well popular simple random sampling technique was applied. Other than that as sample procedure convenience and judgmental method was also used by the researcher.

\section{Table1. Sample Selection}

\begin{tabular}{|l|l|}
\hline $\begin{array}{l}\text { Employees } \\
\text { category }\end{array}$ & $\begin{array}{l}\text { No. of } \\
\text { Employees }\end{array}$ \\
\hline $\begin{array}{l}\text { Managers } \\
\text { (Junior managers \& } \\
\text { Executives) }\end{array}$ & 105 \\
\hline Employees & 105 \\
\hline
\end{tabular}

(Sample survey, 2008)

\subsection{Data for the Study}

Primary and secondary data were collected. As this study is empirical in nature, as far as possible an attempt was made to collect primary data. The questionnaires were designed accurately to measure the attitudes of employees, behavior of leaders and their influence on performance subordinates as well as the leadership styles of managers and leaders.

\subsection{Data Processing, Scaling and Analyzing}

The questionnaire which has been used in this study consists of four boxes ranging from strongly agree (4 marks), somewhat agree (3 marks), agree (2 marks) and disagree (1 marks).respondents are required to highlight item according to the way he/she would most likely behave in the situation. Under each question the respondents' answers were counted and analyzed. The analysis provided a mean of measuring the respondents' preference towards leaders' behavior, leaders' characteristics and performance. Second questionnaire which has been used in this study consisted of a descriptive statement, followed by four possible endings. The respondents (managers and leaders) were asked to indicate the order in which he/she feel each ending applies to you. As you read each statement, assign a letter $\mathrm{A}, \mathrm{B}, \mathrm{C}$ and $\mathrm{D}$ according to the ending you like most " $\mathrm{A}$ " (4 marks), "B" (3 marks), "C" (2 marks) and "D" (1 mark) according to your order of preference.

The mean values of each variable and the average scores (mean values) obtained pertaining to each variable by each respondent was transferred to a master data sheet. All the averages in relation to each variable with respect to each hotel in the sample were calculated in a systematic way using Excel 2003. When analyzing the data collected through the questionnaires the researcher used descriptive statistical tools such as mean, and standard deviation as well as inferential statistical tools correlation, regression and P-value calculated using software (SPSS).

\section{Result and Discussion}

The findings of this study based on the discussions made so far pertaining to leaders' characteristics and leaders' behavior such as leadership styles and 
employee performance with respect to hotels in Sri Lanka are stated below in brief.

- By considering the relationship between leaders' characteristics and leaders' behavior it has been proved by this empirical study that there is a positive strong relationship between the dependent variable performance and independent variable leaders' characteristics.

The table below (Table 2) shows the analysis data collected with regard to leaders traits, values, believes and attitudes along with calculated employee performance values.

Table 2: Leaders characteristics and employee performance (Analysis)

\begin{tabular}{|c|c|c|c|}
\hline 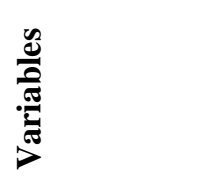 & 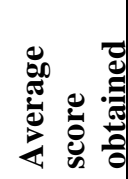 & 司 & 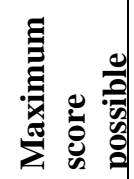 \\
\hline Traits & 3.1 & 0.3 & 4.0 \\
\hline Values & 3.2 & 0.3 & 4.0 \\
\hline Believes & 3.0 & 0.4 & 4.0 \\
\hline Attitudes & 3.5 & 0.3 & 4.0 \\
\hline $\begin{array}{l}\text { Leaders } \\
\text { characteristics }\end{array}$ & 3.2 & 0.3 & 4.0 \\
\hline $\begin{array}{l}\text { Employee } \\
\text { performance }\end{array}$ & 3.0 & 0.4 & 4.0 \\
\hline
\end{tabular}

(Source: Sample Survey 2008)

According to survey data presented in the above table(2) which reveals that leaders' characteristics and performance in the hotel industry are at satisfactory level, since the scores obtained with respect to leaders' characteristics and performance seems to be 3.2 and 3.0 respectively. Table shows the perceived level of leaders trait is 3.1, values are 3.2, believes are 3.0 and leaders, attitudes are 3.5According to these average score obtained for leaders' attitudes is higher than that for other variables. But, perceived level of leaders' believes are less than that for other variables. The standard deviation for trait is 0.3 , value is
0.3 , believe is 0.4 , attitudes 0.3 , the leaders' characteristics is 0.3 and the perceived level of performance is 0.4 , accordingly, it can be understood that the standard deviations with respect to leaders' believes and performance are low.

Table 3: Leaders' behavior and performance

\begin{tabular}{|c|c|c|c|}
\hline 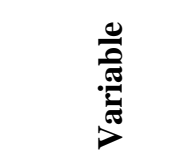 & 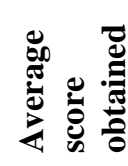 & 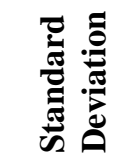 & 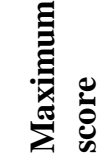 \\
\hline $\begin{array}{l}\text { Delegation } \\
\text { of authority }\end{array}$ & 3.2 & 0.5 & 4.0 \\
\hline $\begin{array}{l}\text { Leadership } \\
\text { styles }\end{array}$ & 3.2 & 0.5 & 4.0 \\
\hline Power & 3.0 & 0.3 & 4.0 \\
\hline $\begin{array}{l}\text { Leaders' } \\
\text { behavior }\end{array}$ & 3.1 & 0.4 & 4.0 \\
\hline performance & 3.0 & 0.5 & 4.0 \\
\hline
\end{tabular}

(Source: Sample Survey data 2008)

Scores obtained with regard to leaders' behavior and employee performance seems to be more than 3.0 , because the maximum score obtainable with respect to each variable is 4.0 .

*Concerning the relationship between the leaders' behavior and employee performance, this empirical study has proved clearly, that there is a positive and direct relationship between leaders' behavior and employee performance. In other words positive change in leaders' behaviour positively affects the employee performance of the hotel. Accordingly the relationship between leaders' behavior and employee performance is significant. Scores obtained with respect to each variable is more than 3.0. The maximum score obtainable with respect to each variable is 4.0. Therefore, the survey results with regard to this variable differ among different individual 
respondents than other variables in the study.

Table 4: Average of leaders' behavior, employee performance and leadership style

\begin{tabular}{|c|c|c|c|}
\hline$\frac{n}{\frac{n}{0}}$ & 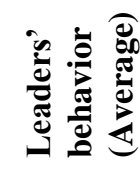 & 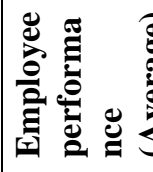 & 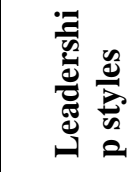 \\
\hline $\begin{array}{l}2,3,4, \\
5,7,11,12 \\
\text { (Total.7) }\end{array}$ & 4.1 & 4.0 & $\begin{array}{l}\text { Democr } \\
\text { atic } \\
\text { Style } \\
\end{array}$ \\
\hline $\begin{array}{l}1,6,8,9,1 \\
0,13,14 \\
\text { (Total.7) }\end{array}$ & 3.6 & 3.7 & $\begin{array}{l}\text { Autocra } \\
\text { tic style }\end{array}$ \\
\hline
\end{tabular}

(Source: survey data 2008)

According to the above table (Table 4) data shows, there are some hotel managers using democratic leadership, where average of (these 7 hotels) leaders' behavior is 4.1 and average job performance is 4.0 in hotels 1 , $6,8,9,10,13$ and 14 are having practiced autocratic type of leadership styles, where average of (these seven hotels) leaders' behavior is 3.6 and average job performance is 3.7. Accordingly it is clear that the leaders' behavior and employee performance vary with the type of leadership style practiced in the hotel industry. Further to that democratic leadership style improves leaders' behavior as well as employees' performance.

*Further to that, it was also scientifically proved that leadership plays a vital role in the hotel industry in determining leaders' behavior and employee performance. Leaders' behavior and employee performance seen to be satisfactory in hotels where the democratic leadership style is practiced rather than in hotels where autocratic leadership style was practiced. It is shown in above table 4.

\section{Conclusion and Recommendation} 5.1. Conclusion

Fifteen star graded hotels have been chosen for this study from all over the country. According to the survey results it can be concluded that the variables, leaders characteristic, leaders behavior and employee performance are interrelated and directly affect the performance of the hotel as a whole. Based on the above findings the researcher made conclusions that leaders' (managers and non-managers) characteristics are individually and together correlated with employee performance of the hotels. Also the suitable leadership styles enhance the employee attitudes and performance, particularly performance in the hotel industry as a whole. When employee performance of hotel industry are increased that will in turn make positive impact on national economy of Sri Lanka.

\subsection{Recommendation}

Based on the findings of the study researcher would recommend the followings to the management of hotels in Sri Lanka in order to improve the performance of employees as well as leaders in the hotels to ensure their contribution towards achieving objectives of the hotel.

* All employees in the hotel industry need to be improved in order to keep their job performance. In order to satisfy employees in the hotels, leaders must understand their problems regarding the development of productivity and quality of their organizations and answering to their personal problems and motivate them to explore and exploit cost effective solution to implementing their development programs, which includes developing capacity of employees and 
perfect services, training the staff members to handle quality work.

* As this study euphorically proved that democratic leadership style contributes to positive behavior and improved employee performance in hotels, it is recommended to implement democratic (participative) leadership style in hotels where it was not practiced.

* Future role of leaders, as how influencing and inspiring subordinates to perform their duties in order to achieve the desired organizational goals. Further it should be mentioned leaders are that leaders are also judged by their behavior as leaders irrespective of the characteristics used to perform duties well. Also it is proposed to adopt a proper method in which all employees are treated equally and their qualifications and achievements are taken into consideration for promotions.

* It is also proposed to look for the possibility of internal recruitment of job vacancies as this will develop positive attitudes among staff.

* The management should introduce a more attractive remuneration system for the lower level workers in the hotels. The management should give their best attention for remuneration packages. Thereby the leaders can get maximum performance level from their employees

* Concerning HRM sector, the personal management is more likely to be insensitive, since they are in a position of privilege and power. Some of them are completely in difference to their roles, and to people dealing with whom they are dealing, they fail to understand the task, which should perform. On the other hand recruitment procedures are revised time to time and training programs should be conducted on time to achieve the objectives and goals.
* Management of the hotels should be identified employees traits, skills, attitudes and personal characteristics. Then management can use new strategy to motivate the employees, and achieve the target.

The researcher has full confidence that when these recommendations are taken into consideration by the management of hotels and they are properly implemented the performance outcome of hotels will certainly be improved. It will in turn make positive impact on national economy in Sri Lanka.

\section{References}

Bennis, W and Goldsmith J (1997), learning to Lead: A work Book on becoming a Leader, Nicholas Brealey Publishing, London.

Blak. R. and Mouton, J.S. "The new Managerial grid", Gulf Publishing company, 1978, p-11

Breckler.S.J(1984), 'Empirical Validation of Affect, behaviour and cognition as Distinct Components of Attitude", Journal of Personality and Social Psychology, May,pp 1191-1205.

Carter L. and Mary Nixon, "Ability, Perceptual, Personality and Interest Factors associated with different criteria of Leadership", Journal of Psychology, 27 (1949), pp.377- 388 .

Eugene E. Jennings, An Anatomy of Leadership (New York, N.Y. Mc Graw-Hill, 1960), pp15.

Fiedler, F.E. "The leadership Game: Matching the man to the Situation". 
Organizational Dynamics, vol.2 (1978) pp.59-111.

Fleishman E.A. Harris E.F. and Burtt H.E. Leadership and supervision in industry (Columbus, Ohio; Burean of Ed. Research, 1955) No.33

Gardener G. Functional Leadership and popularity in small groups", 1956.

Goode O.S. and Day, D.R." The good leader behavior incorporation, 1963, pp-127-132

Haythorn. W. couch A. Haefner, Langhan.P. "The effect of varying combinations of authoritarian \& equalitarian leaders and follower", Journal of Abnormal and Social Psychology (1956) pp 210-219.

Helen H.Jennings, Leadership and Isolation(New York: Longmans, Green 1943).

Polansky.R.Lippitt and Redl. F. "The use of near-Sociometric data in Research on Group Treatment Process", 13(1950),pp 39-62.

Hersey.P and Kenneth .H.Blancard, "Management of Organizational Behavior", Prentice Hall, 1988, pp169-201.

Hollander, Leaders, groups and influence.

Jacobs. T O (1971),’Leadership and Exchange in Formal Organizations", Human Resources Research Organization, Alexandria,

Jago, Arthur G. Leadership, Perspectives in Theory and Research", Management Science, March 1982.
Jit S. Chandan, Organizational Behaviour, 1998.

Katz. D (1690), “The Functional Approach to the study of attitude change", Public Opinion Quarterly, 24, pp163-204.

Kraus. SJ (1995), Attitudes and the Prediction of Behaviour, A Metaanalysis of the Empirical Literature", Personality and Social Psychology Bulletin, January, pp. 58-75.

Lewin K.Lippitt. R.”An Experimental Approach to the Study of Autocracy and Democracy, 1938, pp293-300.

Luthans.F(2002), “Organizational Behaviour", Mc Graw Hill, New York.

Stogdill. R M (1976),"Handbook of Leadership", the Free Press, New York.

Szilagyi A. and M.Wallace, "Organizational Behaviour and performance", Scott, Foresman, 1983, pp274-276. 